\title{
Coastline Security Engineering Using Geo-Spatial Approach: Case of Chabahar Port, Iran
}

\author{
Sharareh Pourebrahim1*, Mehrdad Hadipour'2, Mazlin Bin Mokhtar ${ }^{3}$ \\ ${ }^{1}$ Department of Environment, Faculty of Natural Resources, University of Tehran, Tehran, Iran \\ ${ }^{2}$ Department of Environment, Faculty of Agriculture and Natural Resources, Arak University, Arak, Iran \\ ${ }^{3}$ Institute for Environment and Development (LESTARI), National University Malaysia (UKM), Bangi, Malaysia

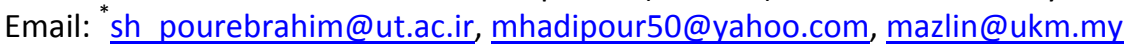

Received 7 Aril 2014; revised 7 May 2014; accepted 17 May 2014

Copyright (C) 2014 by authors and Scientific Research Publishing Inc.

This work is licensed under the Creative Commons Attribution International License (CC BY).

http://creativecommons.org/licenses/by/4.0/

c) (i) Open Access

\begin{abstract}
Regarding the special potential of ports located on international coastlines such as Makoran Sea (Iran) for goods and human smuggling, national level of coastline security is very important. They can play a significant role in the development of power and security. Based on military reviews and analyses, police location and monitoring field view in the coastlines are strategic issues in modern security development. This research proposes a tool for development of coastal roads and coastal walking routes in the deployment of police. The main focuses are monitoring field view and accessibility to the strategic coastline. GIS tool plays an essential role in producing important security maps. Chabahar Port in Iran, as the most important port of Makoran Sea, has been selected as the study area, regarding its strategic role in the national economy and security. Research method focused on these major axes: successful establishment of police stations in shoreline for increasing monitoring and coastal security and suitable patrol of patrol police car in the coastal roads. This study adopts a scientific approach to the analysis of the present and future development in urban and security planning in coastal towns in the national and regional levels.
\end{abstract}

\section{Keywords}

Security, Coastline, Geo-Spatial Approach

\footnotetext{
${ }^{*}$ Corresponding author.
}

How to cite this paper: Pourebrahim, S., Hadipour, M. and Mokhtar, M.B. (2014) Coastline Security Engineering Using Geo-Spatial Approach: Case of Chabahar Port, Iran. Journal of Geographic Information System, 6, 236-245. 


\section{Introduction}

Urban Development always happens rapidly and intensively, resulting in contingent environmental problems [1]. The consequences of rapid industrialization and urbanization are far reaching and affect local and regional security. The economy greatly depends upon the urban activities. Additionally, coastal towns are more important in this issue with regard to national marine businesses and activities [2] accordingly, this importance should warrant special consideration from the military and security points of view for ports and coastal towns. Coastal zones are the bridges of communication and interaction between countries, facilitating internal and external country relationships to maintain regional balance using geographical locations and ensuring the safety of the interior by sea borders. They also collectively operate as a symbol of the country's development. Ecological resources and major economic activities change the coastal zones to the most sensitive and valuable areas in the world. Iran plays a strategic role in the Middle East with regard to its important bodies of water. The Makoran Sea, the Persian Gulf and the Strait of Hormuz are the most strategic locations in the world. Unfortunately, the above-mentioned issues also involve undesirable social effects such as illegal immigration and the smuggling of goods and humans. The increasing population in the coastal zones produces major economic and commercial activities. These activities cause an increasing susceptibility and underscore the importance of coastal security. The accessibility of police and military stations to coastal zones (the above-mentioned areas with social sensitivity) can be one of the most important concepts and ultra-structural factors in the development of coastal towns.

The necessity of paying attention to accessibility and the field view as two key military and security elements in urban planning has been focused on by many experts [3] and [4]. A quick review of the available research shows various formulas and models in this field. But there is no special focus on coastal towns' security. They place emphasis on different factors and priorities. Many of the above-mentioned studies are designed in a GIS environment [5]. With regard to the important role of GIS in planning and urban policies, this study attempts to produce concurrent accessibility and security in coastal areas. Coastal security must be focused on the development and deployment of military and police centers. These corresponded to the suitable location of police stations along the coastal shoreline. Chabahar port has been selected as the study area due to the importance and value of its economy, trade, transit and security. The development of Chabahar port creates a wide framework to create jobs and economic prosperity in the region. The main reasons for this selection can be summarized as follows:

- Necessity of improvement in urban policy and security in Iranian coastal areas

- socio-economic potential of Chabahar as the most important port of the Makoran sea

- Strategic geographical position of Chabahar and its security challenges

\section{Importance of Coastline Security}

The security of coastal towns depends upon the coastlines and their associated infrastructure. Coastlines automatically manage ongoing efforts to the security of offshore port landuse. They are also the main entrance of the extraordinary demands on the port authorities and other relevant issues with port security [6].

The coastline in a security-operational environment is complex and includes the regions of sea, land and air. To successfully support the current and future security operations of the coastline, geospatial information must be rapidly integrated and analyzed to meet the ongoing force structure evolution and new mission directives [7]. With regard to the specific role of the coastline in the security of the coastal area, the fundamental focus has been on the military to develop port and coastal town security. Concerning the types and numbers of crime from coastlines, military restrictions on coastline activities are necessary. The challenge is to find a practical way of handling this issue. This research attempts to find the best combination of military solutions to meet this challenge.

\section{Identification and Interpretation of the Coastline Security Factors}

Based on the Pressure-State-Response approach, the indicators in the system were divided into spatial interpolation and non-spatial interpolation, also the warning method was classified into security, sub-security and insecurity [8]. With respect to coastal security importance in the study area, above classification is summarized and calibrated to security and insecurity.

There are 3 types of security tools for the coastlines of Iran [9]: permanent police stations, temporary police sites for policemen to patrol on foot, and patrol police cars. 
Coastal security planning by police centers includes two steps: the observation of phenomena and the on-time deployment of policemen to the location of the coastal phenomenon. Therefore, the security of coastal towns can be affected by the following parameters:

- Number of permanent and temporary coastal police sites

- Distribution of permanent and temporary coastal police sites along the coastline

- Field view of the policemen during their movements (walking and police car patrol)

- Accessibility of police to coastline

In the Chabahar port, there is only one permanent police center (Figure 1). For the location of temporary coastal police sites, there is no limitation; the number of sites can be increased and reduced according to security requirements. The location of the permanent police center shows that it can only be the directory center and cannot be used for practical monitoring of the coastline.

The field views of the policemen during car patrol follow the route (road). With respect to the above notes, there are semi-fixed values for the following two items: the field view of the policemen during car patrol and the accessibility of the permanent police center to the coastline. Therefore, the location of the temporary coastal police sites as a flexible parameter can play an important role in coastal security engineering. Based on this interpretation, the methodology of the research includes the following steps:

- Spatial and quantitative analysis of the field view to the coastline

- Spatial and quantitative analysis of the accessibility of the coastline

- Location planning of temporary coastal police sites

\section{Spatial and Quantitative Analysis of Coastline Security Engineering}

Security issues of a nation's coastlines must be examined from the perspective of associated infrastructures [6]. Ongoing efforts to secure coastline as well as the patrol networks, field view and police facilities must be surveyed. As mentioned earlier, the field view is an important factor for coastline security planning. This factor of police duty can be evaluated via two basic situations: policeman walking on patrol and policemen patrolling by car. The normal angle accuracy of the human field of view in the static situation is $170^{\circ}$ [10], and the distance accuracy depends upon the importance of the view; for the issue of security monitoring, the distance can be considered to be 30 meters [10]. During movement, this distance is affected and is reduced by the movement speed. This effect can be calculated by a mathematical vector analysis [11] based on Figure 2 and Equations (1)-(3):

Based on the following mathematical vector calculation:

$$
\begin{gathered}
O D^{2}=O B^{2}+O A^{2}+2 \cos \alpha \cdot O A \cdot O B \\
O C=\cos \beta \cdot O D \\
O E=\cos 5 \cdot O C
\end{gathered}
$$

In coastal security monitoring, the average speed of police car patrol and policeman walking are $11 \mathrm{and} 2 \mathrm{~m} / \mathrm{s}$, respectively [9]. Regarding the negative impact of speed on the distance view, the amounts of OA (passed distance after one second) are considered with a minus sign $(-11$ and -2$)$ :

OA for police car patrol $=11 \mathrm{~m}$

OA for policeman walking $=2 \mathrm{~m}$

OD for police car patrol $=31.04 \mathrm{~m}$

OD for policeman walking $=29.89 \mathrm{~m}$

$\beta$ for police car patrol $=30.16^{\circ}$

$\beta$ for policeman walking $=5.87^{\circ}$

OC for police car patrol $=9.64 \mathrm{~m}$

OC for policeman walking $=26.47 \mathrm{~m}$

OE for police car patrol $=9.54 \mathrm{~m}$

OE for policeman walking $=26.37 \mathrm{~m}$

Therefore, the calculation results show that the field views of the policemen during car patrol and walking cover a distance of 9.64 and 26.47 meters, respectively, and the maximum location distances to support these field views are 9.54 and 26.36 meters.

Access time to coastline during police duty can also be evaluated by the above-mentioned basic situations (policeman walking and police car patrol). After the observation of crime cases along the coastline, the policeman 


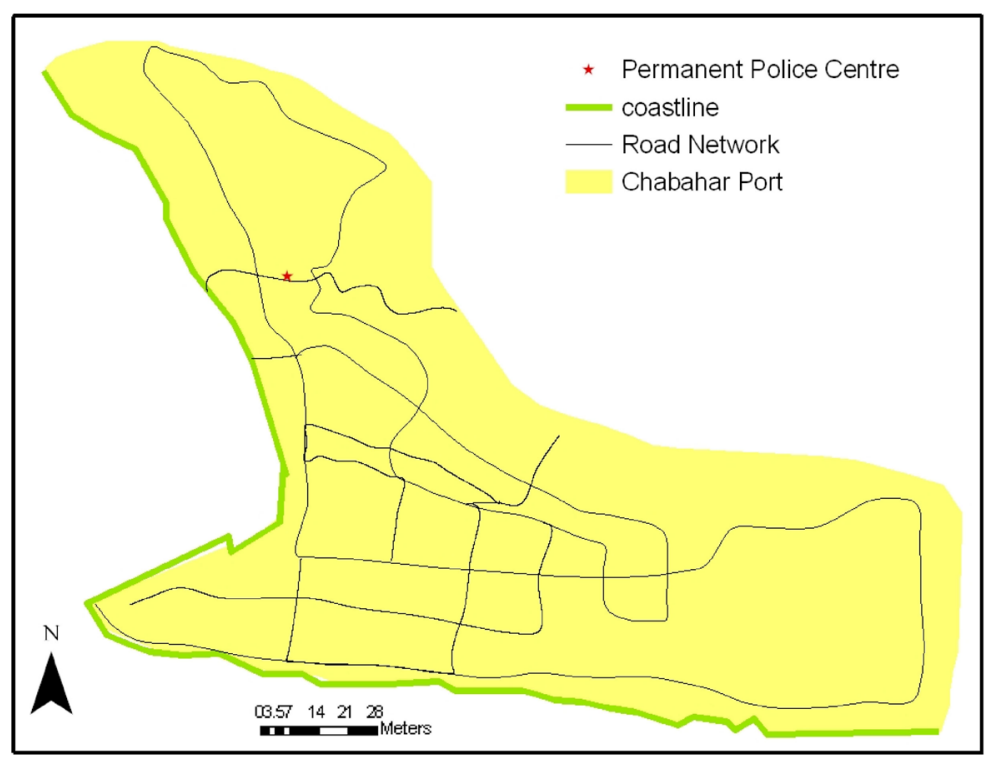

Figure 1. Location of Chabahar permanent police center.

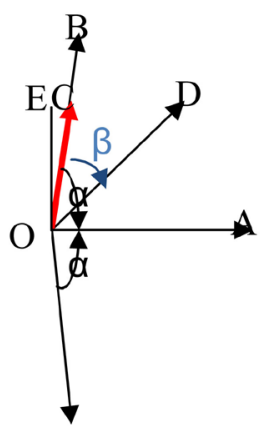

$\mathrm{OA}=$ Passed distance after one second $\mathrm{OB}=$ Distance view in static situation (one second) =

$30 \mathrm{~m}$

$\mathrm{OC}=$ Distance view in moving situation

$\alpha=($ Normal view angle $) / 2=85^{\circ}$

$O D=$ outcome vector of $O A$ and $O B$

$\mathrm{OE}=$ Police location distance to support distance view

Figure 2. Thematic map of coastline security analysis.

should access the crime location in an acceptable reaction time. Normally there is no extended road reaching all locations on the coastlines; therefore, the best way to access the crime location for all coastal policemen (on foot or car passenger) is running on the beach. The average human running speed is approximately $4 \mathrm{~m} / \mathrm{s}$ [12], and the primary police reaction time is approximately 1 second for a walker and 5 seconds for a car passenger [13]. Hence, after the observation of a crime at the maximum distances mentioned above ( $9.54 \mathrm{~m}$ and $26.37 \mathrm{~m})$, the coastal crime location can be reached in approximately 15 seconds, which covers running and the primary reaction time. This is a very short and suitable access time. It shows that there is no security challenge in the issue of the access time. Hence, coastline security can be evaluated just by a location analysis of the field view of policemen during movement (9.54 and 26.37 meters).

\section{GIS Mapping of the Secure and Insecure Coastline}

As mentioned above, secure and insecure coastlines are located in the field view of the policemen during movement. The field view of policemen as passengers in a car includes 9.54 meters of buffer zone of the road network. A relevant map is produced using the buffering option in the ArcGIS environment. Normally, coastlines located in these zones are secure coastlines (Figure 3).

The security of other coastlines (insecure coastlines in Figure 3) should be supported by another method: policemen to patrol on foot. With respect to the field view of policemen while walking, the maximum distance of their walking route from the insecure coastline is $26.37 \mathrm{~m}$. This distance is shown in Figure 4.

As the road location is fixed, there is minimum flexibility in the field view of car passenger policemen; however, the field view of walking coastal policemen can be changed based upon the location of the walking route. 


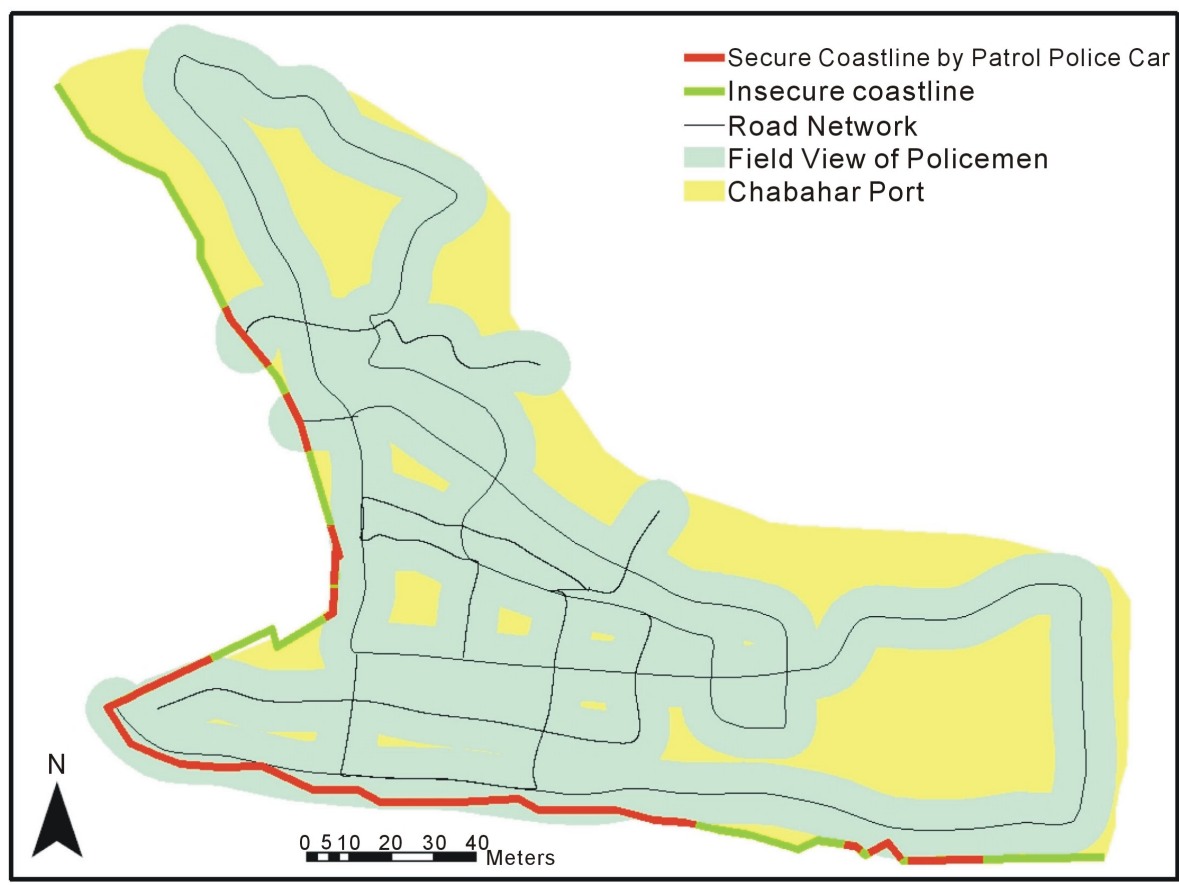

Figure 3. Map of coastline security by patrol police car.

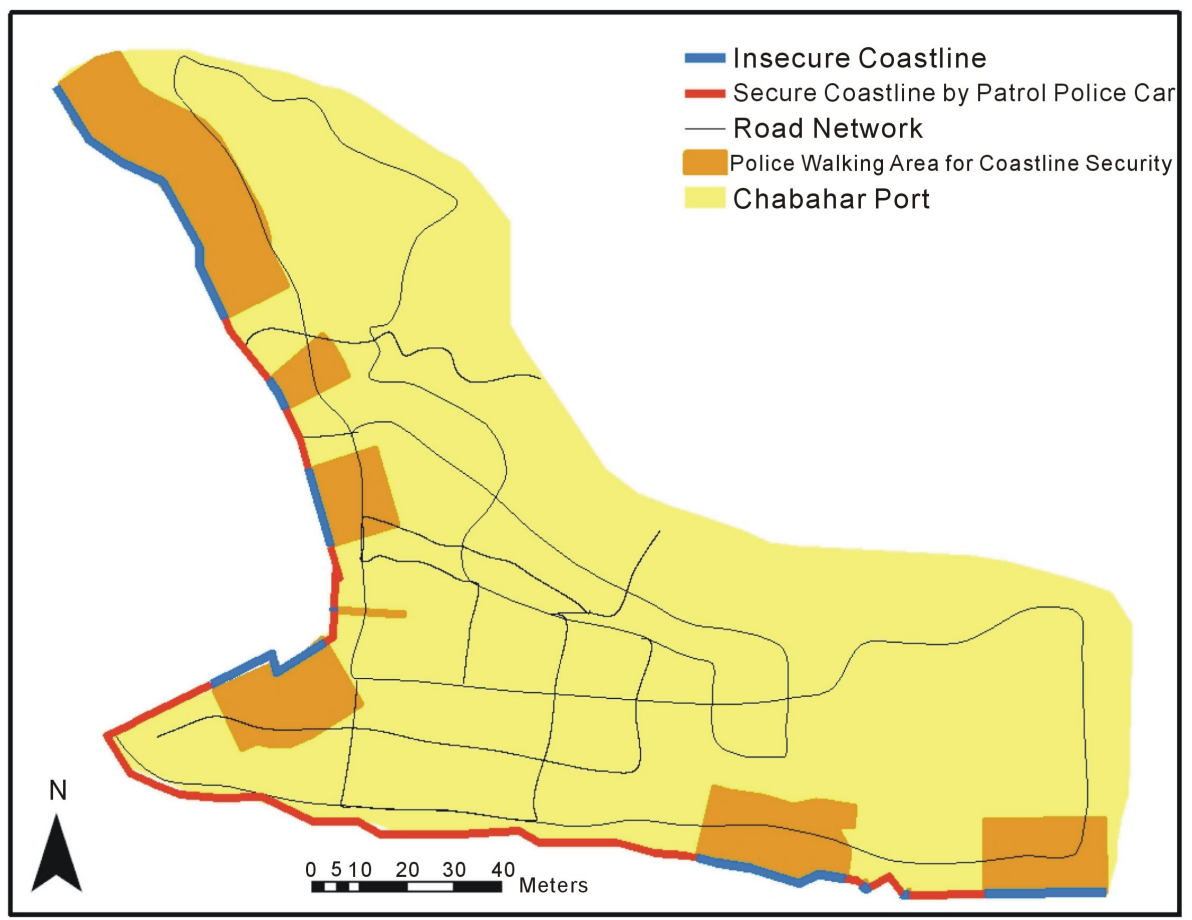

Figure 4. Map of maximum coastline patrol by walking police.

According to this flexibility, the selection of the maximum distance for the walking route is not only unnecessary, but it also is better to select the minimum possible distance. There are two main reasons, at first avoiding an interaction between the police walking route and other land uses and then upgrading the field view of the policemen. For the selection of the minimum distance for the walking route, there is only one limitation: the daily elevation and heading away of the sea water in the coastal area. The maximum daily sea water heading away in 
the coastal area of Chabhar is 10 meters [14] therefore a reasonable distance from the coastline (for the designation of a coastal walking route) can be considered to be approximately 12 meters.

\section{Upgrading of Coastal Police Field View by Minimizing the Distance of the Walking Route}

Minimizing the distance of the coastal walking route for policemen can upgrade their field of view. Figure 5 demonstrates this.

For the selection of the maximum distance for the police walking route, the parameters are as follows:

$$
\begin{gathered}
\alpha=90-85=5^{\circ} \\
O A=A B \times \cos \alpha=26.34 \mathrm{~m} \\
(O B)^{2}=(A B)^{2}-(O A)^{2}=(26.47)^{2}-(26.37)^{2} \\
O B=2.3 \mathrm{~m}
\end{gathered}
$$

In this situation, only $2.3 \mathrm{~m}$ of coastline is therefore supported by the police field view per second. By considering a reasonable distance from the coastline $(12 \mathrm{~m})$, the supported coastline can be increased to $23.59 \mathrm{~m}$ per second as follows:

$$
\begin{gathered}
O A=12 \\
(O B)^{2}=(A B)^{2}-(O A)^{2}=(26.47)^{2}-(12)^{2} \\
O B=23.59 \mathrm{~m}
\end{gathered}
$$

\section{Success of Analyzing the Coastline Security Monitoring}

As mentioned above, there are two possible practical options for the security development of the study area: patrol police cars and policemen patrolling on foot. These options will be successfully completed by the following implementations:

- Location of a sufficient number of police stations at a suitable distance (12 m) from the coastline

- Continuous patrol of enough police cars on coastal roads

\subsection{Location of Enough Police Stations at a Suitable Distance from the Coastline}

The location of police stations at a suitable distance from the coastline depends upon the walking speed of the policemen. As mentioned earlier, by locating the police at a $12 \mathrm{~m}$ distance from the coastline, the security of 23.59 $\mathrm{m}$ of coastline can be supported at the moment. If two policemen walk in opposite directions, then their common walking area is simultaneously supported by their field view. This means that their police stations (walking starting points) should be located within a distance of $23.59 \mathrm{~m}$ from each other. Hence, for the current security monitoring of coastline by patrol walking, one police station with two policemen should be located at a $23.59 \mathrm{~m}$ distance from other stations (Table 1).

\subsection{Continuous Patrol of Enough Police Cars on the Coastal Roads}

The location of efficient coastal roads and the police car speed is not flexible, and the security efficiency of the field of view in coastal roads is fixed. Therefore, there is only one flexible parameter to upgrade the security efficiency of patrol police cars, which is the number of port police cars on the coastal roads. With regard to the security significance of the distance of the road from the coastline, this parameter is categorized to calculate field view changes. The road situations of the study area are evaluated by the extension of the x-tools of the ArcGIS software. After this GIS evaluation, $5 \mathrm{~m}$ and $8 \mathrm{~m}$ are identified as the two main average road distances from the coastline. These two average road distances divide efficient coastal roads into two main parts (named according to Codes 1 and 2) as shown in Figure 6 and Table 2.

The supported coastlines for these two parts have been calculated by a process that is similar to that of the policemen's coastal walking route.

With respect to police car speed on the coastal roads $(11 \mathrm{~m} / \mathrm{s})$, the required police cars are shown in Table 3 . 


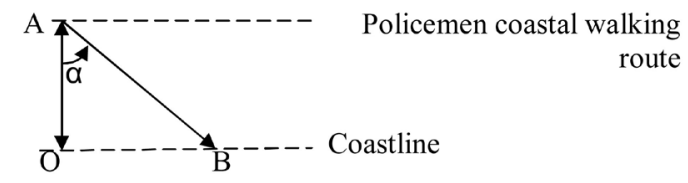

$\mathrm{OA}=$ Distance of walking rout from coastline $\mathrm{AB}=$ View Radius $=26.47 \mathrm{~m}$ $\mathrm{OB}=$ Covered Coastline by view radius

Figure 5. Thematic map of upgrading the coastline field view.

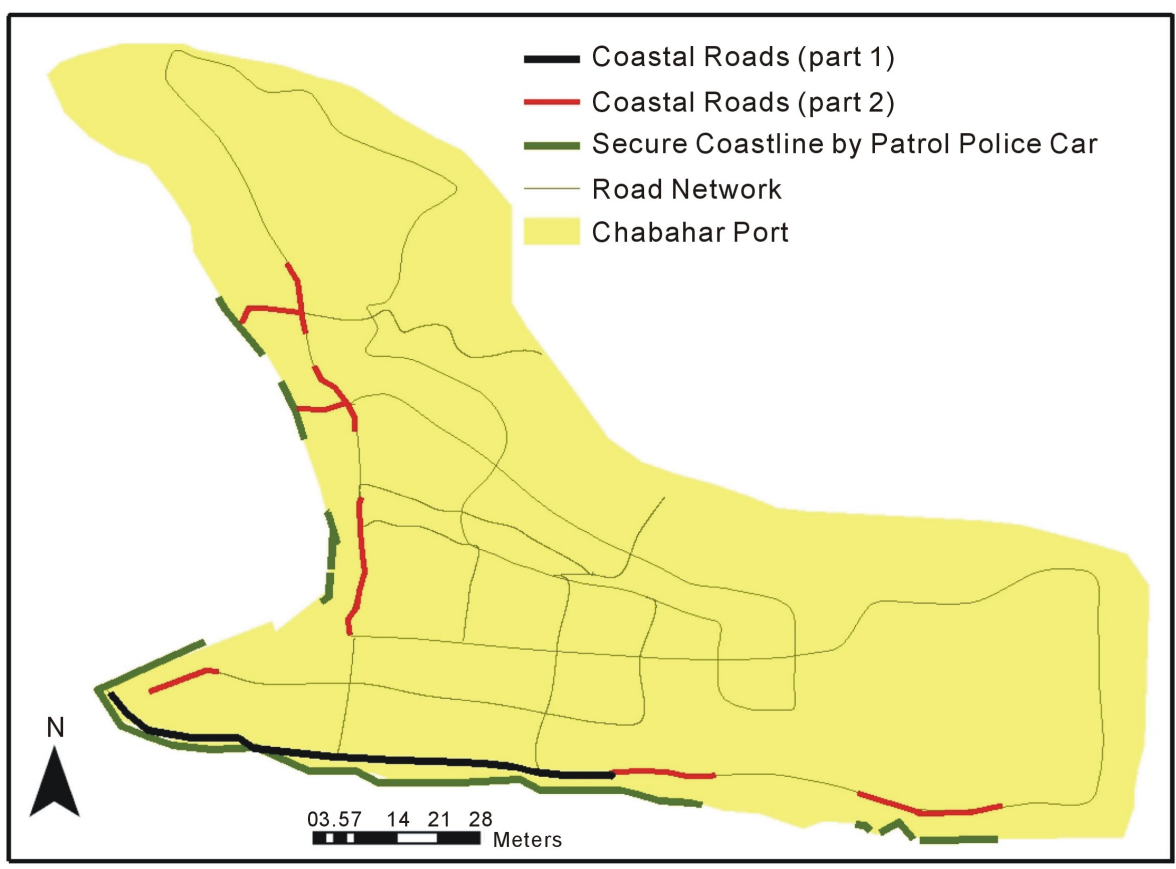

Figure 6. Map of coastal roads in the study area.

Table 1. Location properties of coastline police stations.

\begin{tabular}{ccc}
\hline Number of Policemen in the Station & Station Distances to Coastline & Supported Coastline (Distance between Station) \\
\hline 2 persons & $12 \mathrm{~m}$ & $23.59 \mathrm{~m}$ \\
2 persons & $26.37 \mathrm{~m}$ & $2.30 \mathrm{~m}$ \\
\hline
\end{tabular}

Table 2. Coastal road properties in the study area.

\begin{tabular}{ccc}
\hline Part Code & Average Road Distances to Coastline & Supported Coastline \\
\hline 1 & $5 \mathrm{~m}$ & $8.1 \mathrm{~m}$ \\
2 & $8 \mathrm{~m}$ & $5.1 \mathrm{~m}$ \\
\hline
\end{tabular}

Table 3. Required police car for coastal road of the study area.

\begin{tabular}{ccc}
\hline Part Code & Used Road Length & Required Police Car for Used Road Length \\
\hline 1 & 16 & 2 \\
2 & 10 & 2 \\
\hline
\end{tabular}

Hence, for the current security monitoring of the coastline, two police cars should move in opposite directions along road lengths of 16 and 10 meters.

\section{Results}

In fact, the result is the identification of safe beaches in the study area through the combination of the following 
two main security factors: patrol police cars and policemen patrolling on foot. This result is accomplished by the suitable location of police stations at the correct distance from the coastline and the suitable continuous patrol of police cars on the urban coastal roads. Currently, the security monitoring of the coastline by port walking should involve one police station with two policemen located at a $23.59 \mathrm{~m}$ distance from other stations (Table 1 ). As the total length of the coastline secured by policemen walking is approximately $300 \mathrm{~m}$, for current security developments, 13 police stations and 26 policemen are required. By the same process, the required facilities for the current security development of the coastline by police cars are shown in Table 4.

Therefore, the total facilities currently required for the security monitoring of the Chabahar coastline are 102 policemen, 13 police stations and 38 police cars. Considering the shift working time of the police organization [9], the number of policemen will be increased to 306 persons per day. Economically, these numbers are not reasonable or possible. To make security possible, some re-evaluation of the situations can be performed. The first evaluation parameter is the security monitoring time. The calculations and results presented here focus on the current security monitoring of the coastline, which covers 1 second of time. In this type of monitoring, the reaction time for the marine offenders is automatically considered to be 1 second, but this time can be increased to an average of 8 seconds by considering certain parameters, such as vessels riding and alighting [13]. By the consideration of this reaction time, the total required facilities for the security monitoring of the Chabahar coastline will become 123 policemen, 3 police stations and 6 police cars per day. Regarding the separate segments of the supported secure coastline, the total required facilities cannot be less than 20 cars, 7 police stations and 162 policemen per day. This estimate seems more reasonable, but there is an even better choice. In recent calculations, part 2 of the coastal roads needs 18 cars and 108 policemen. If the security type of the supported coastline for this part is changed to walking policemen, then by primary evaluation, the required facilities will become only 6 stations and 36 policemen. Additionally, in this primary evaluation, the positive effects of coastline integration have not been considered; therefore, this coastline should certainly be assigned for security patrols by walking policemen. This merging has the following two main advantages: reducing the required numbers of coastal security facilities and integrating the coastal security facilities of the integrated coastline segments.

Currently, the total required facilities for the security monitoring of Chabahar coastline is 5 police stations, 2 police cars and 42 policemen per day. The recommended police station locations are shown on the final map of the security monitoring of Chabahar coastline (Figure 7). There are some parts with interactions between the road network and the police walking route. In these parts, there are some additional considerations that will be presented in the discussion and conclusion.

\section{Results and Discussion}

Organizing and characterizing the various factors associated with coastal roads, coastlines and locating security centers can produce a prediction tool to provide coastal town security. This tool also provides security values for the development of coastal areas. Policymakers can correct the situation and make plans for the future to assist in the development of coastal towns. An appropriate designation of the coastal security systems is discussed in this paper. In this context, communication between the police field view and the access and security of the coastal cities can provide the groundwork for the design of better security systems. To identify and assess the security parameters of the coastline in the study area, the development priorities below that will improve access to military facilities in the coastal zone are suggested:

1) Increasing road construction, especially access to beaches

2) Annual assessment of police station locations

3) Using other portal coastline security facilities, such as special motorcycles

4) Outfitting the coastline with more modern facilities, such as lights and cameras

5) Special education of policemen who will patrol on foot

6) Designation of special corridors in the interaction locations of walking routes and roads

7) Small changes in the walking routes and in the interaction locations of walking routes and roads

Table 4. Total required security facilities for coastal road of the study area.

\begin{tabular}{cccc}
\hline Part Code & Part Length & Required Police Car & Minimum Required Policemen \\
\hline 1 & $190 \mathrm{~m}$ & 12 & 24 persons \\
2 & $260 \mathrm{~m}$ & 26 & 52 persons \\
\hline
\end{tabular}




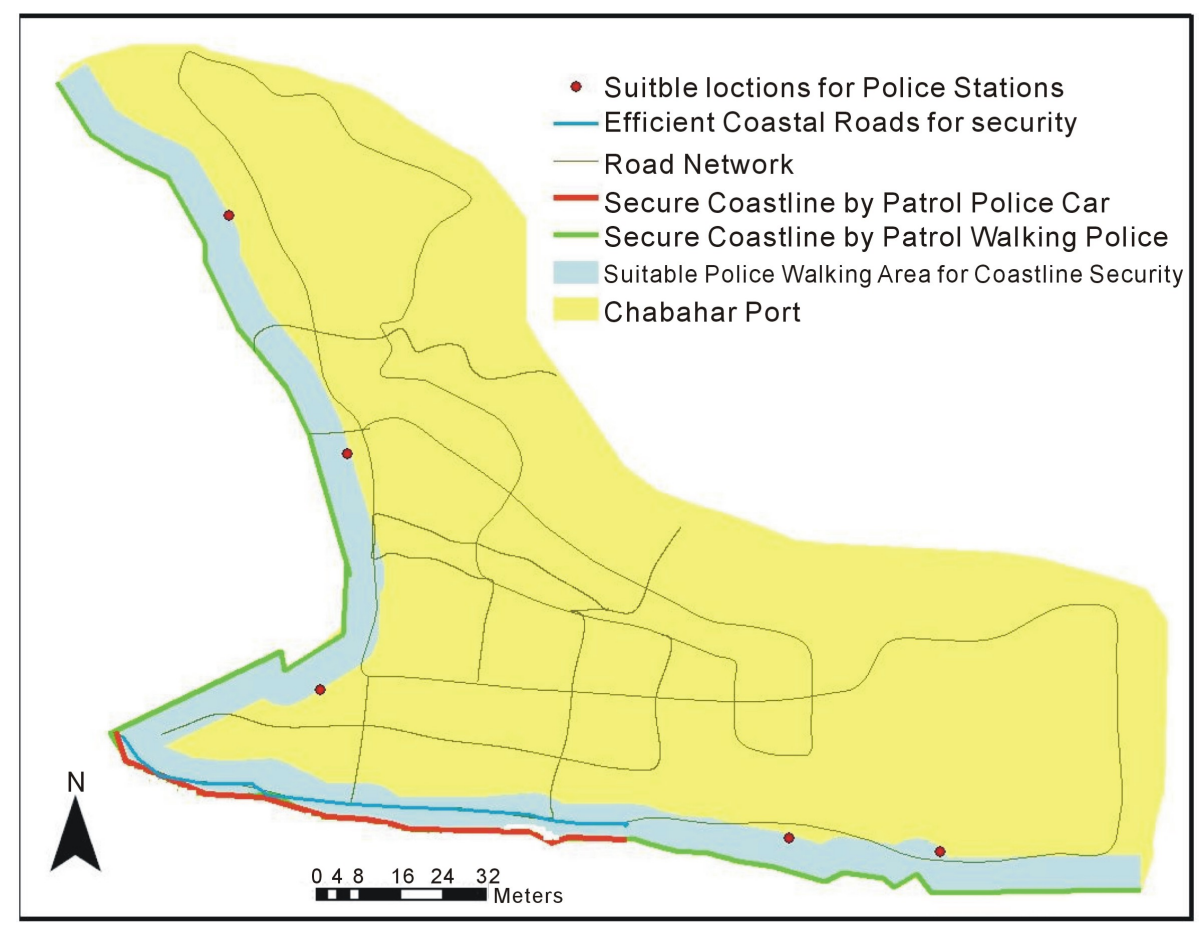

Figure 7. Final map of security monitoring of the Chabahar coastline.

This paper successfully manages the military development priorities to upgrade the security of coastal areas. Some other remarks are also necessary to complete this development. Guards and patrol forces near the coastal areas should be increased at special times and in special zones. Suitable patrol establishments at the right time and at the appropriate interval distances are necessary to maximize the contribution of development priorities. Military and security experiences suggest that these facilities should always be placed within a certain range of the coastline.

\section{Acknowledgments}

We acknowledge the Institute for Environment and Development, UKM, Malaysia, and University of Tehran and Arak University, Iran for their provision of resources and collaborative efforts. We also acknowledge help from the following grants for this study. UKM-AP-2011-23, and UKM-DLP-2011-083, BG-A-XXX100100 MOE Malaysia; JSPS Asian Core Programme MOHE; and LRGS grant 203/PKT/6720004 (Programme 203/ PKT/6724003).

\section{References}

[1] Xiao, J. (2011) Urban Ecological Security Evaluation and Analysis Based on Fuzzy Mathematics. Procedia Engineering, 15, 4451-4455. http://dx.doi.org/10.1016/j.proeng.2011.08.836

[2] Barker, A. (2005) Capacity Building for Sustainability: Towards Community Development in Coastal Scotland. Journal of Environmental Management, 75, 11-19. http://dx.doi.org/10.1016/j.jenvman.2004.11.002

[3] Bagaeen, S.G. (2006) Redeveloping Former Military Sites: Competitiveness, Urban Sustainability and Public Participation. Cities, 23, 339-352. http://dx.doi.org/10.1016/j.cities.2006.05.002

[4] Kennedy, H., Farrell, T., Paden, R., Hill, S., Jolivet, R., Willetts, J. and Rising, S.S. (2009) “I Wasn’t Alone”-A Study of Group Prenatal Care in the Military. Journal of Midwifery \& Women’s Health, 54, 176-183. http://dx.doi.org/10.1016/j.jmwh.2008.11.004

[5] Kotavaara, O., Antikainen, H. and Rusanen, J. (2011) Population Change and Accessibility by Road and Rail Networks: GIS and Statistical Approach to Finland 1970-2007. Journal of Transport Geography, 19, 926-935. http://dx.doi.org/10.1016/j.jtrangeo.2010.10.013

[6] Emerson, S. and Nadeau, J. (2003) A Coastal Perspective on Security. Journal of Hazardous Materials, 104, 1-13. 
http://dx.doi.org/10.1016/S0304-3894(03)00230-9

[7] Fleming, S. (2009) GIS Applications for Military Operations in Coastal Zones. Journal of Photogrammetry and Remote Sensing, 64, 213-222. http://dx.doi.org/10.1016/j.isprsjprs.2008.10.004

[8] Li, Y.F., Sun, X., Zhu, X.D. and Cao, H.H. (2010) An Early Warning Method of Landscape Ecological Security in Rapid Urbanizing Coastal Areas and Its Application in Xiamen, China, Ecological Modelling, 221, 2251-2260. http://dx.doi.org/10.1016/j.ecolmodel.2010.04.016

[9] Islamic Republic Iran Police (IRIP) (2012) Police Service Instruction.

[10] Zendedel, K. (2010) How Can We Build the Natural Order Architecture? Chekame, Iran.

[11] Hay, G.E. (2012) Vector and Vector Analysis. Dover Publications, Mineola, New York.

[12] Gazendam, M.G.J. and Hof, At L. (2007) Averaged EMG Profiles in Jogging and Running at Different Speeds. Gait \& Posture, 25, 604-614. http://dx.doi.org/10.1016/j.gaitpost.2006.06.013

[13] Yuhas. D. (2013) Speedy Science: How Fast Can You React? A Swift Science Activity from Scientific American.

[14] Iranian National Oceanography Institute (INOI) (2013) Tide Report of Makoran Sea. 